\title{
Potencialidades da Mídia Independente como referencial didático no Ensino Médio para o combate ao Racismo Ambiental
}

\author{
Elissandro dos Santos Santana \\ Professor da Faculdade Nossa Senhora de Lourdes - FNSL (Porto Seguro) \\ Professor do ECE - Evolução Centro Educacional (Porto Seguro) \\ Revisor da Revista Latinoamérica \\ Colaborador, tradutor e colunista de sustentabilidade/meio ambiente do Portal Desacato \\ $\triangle$ elissandross@gmail.com
}

Recebido em 18 de abril de 2018

Aceito em 14 de junho de 2018

\begin{abstract}
Resumo:
Esta é uma sugestão de pesquisa em torno das potencialidades da mídia independente como referencial didático no Ensino Médio para uma formação crítica de combate às injustiças e ao racismo ambiental. Como proposta sugestiva, o locus objeto de estudo escolhido foi o CIEPS - Complexo Integrado de Educação de Porto Seguro - e o nível básico de execução foi o Ensino Médio, mas poderia ser outro, dado que a pesquisa poderia ser executada em qualquer espaço escolar, período e ano do Ensino Fundamental e Médio da Educação Básica brasileira. Cabe destacar que o trabalho em questão, além de contribuir para novas perspectivas de análise no que tange à arte do tema proposto, se configura como espaço para reflexão acerca dos processos e dos caminhos de pesquisa que poderão se desenrolar em uma proposta de investigação científica despontando como oportunidade para a alfabetização científica de graduandos e de pós-graduandos com dificuldades para elaboração de projetos de pesquisa para as seleções em todo o país. Para a discussão, apresentam-se algumas considerações iniciais sobre a importância da pesquisa, referências teóricas que poderão consubstanciá-la, possibilidade de problema de investigação, demonstrações e procedimentos para a condução da pesquisa-ação, provável produto final e resultados esperados.
\end{abstract}

Palavras-chave: Mídia Independente, Referencial Didático, Ensino Médio, Racismo Ambiental.

\section{Potentialities of the Independent Media as a didactic reference in High School to combat environmental racism}

\begin{abstract}
:
This is a research suggestion regarding the potential of the independent communication media as a didactic reference in Middle School for a critical training in the fight against injustice and environmental racism. As a suggestive proposal of research, the chosen object of study was the CIEPS - Integrated Education Complex of Porto Seguro and the basic level of execution was the Middle School, but the choice could be another totally different one, given that the research could be carried out in any school space, level, period and year of the Fundamental and Middle Teaching of Brazilian Basic Education. It should be noted that the work in question, in addition to contributing to new perspectives of analysis in regard to the art of the proposed topic, is configured as a locus for reflection on the processes and research paths that may be developed in a proposal of scientific research and emerges as an opportunity for the scientific literacy of graduates and postgraduates with difficulties for the elaboration of research proposals for postgraduate selections throughout the country. For the elaboration of the whole discussion, some initial considerations about the importance of the research proposal, theoretical references that could substantiate the research, a possibility of research problem, demonstrations and procedures for conducting the action research, probable product final and expected results.
\end{abstract}

Keywords: Independent Media, Didactic Reference, Secondary education, Environmental Racism. 


\title{
Potencialidades de los Medios Independientes como referencial didáctico en la Enseñanza Media para el combate al racismo ambiental
}

\begin{abstract}
Resumen:
Esta es una sugerencia de investigación en torno a las potencialidades de los medios independientes de comunicación como referencialidades didácticas en la Enseñanza Media para una formación crítica de combate a las injusticias y al racismo ambiental. Como propuesta de pesquisa, el espacio objeto de estudio escogido fue el CIEPS - Complejo Integrado de Educación de Porto Seguro - y el nivel básico de ejecución fue la Enseñanza Media, pero la escoja podría ser otra totalmente distinta, dado que la investigación podría ser ejecutada en cualquier espacio escolar, nivel, período y año de la Enseñanza Fundamental y Media de la Educación Básica brasileña. Cabe destacar que el trabajo en cuestión, además de contribuir a nuevas perspectivas de análisis en lo que se refiere al arte del tema propuesto, se configura como locus para reflexión acerca de los procesos y de los caminos de investigación que podrán desarrollarse en una propuesta de investigación científica y despunta como oportunidad para la alfabetización científica de graduados y de postgraduados con dificultades para la elaboración de propuestas de investigación para las selecciones de postgrado en todo el país. Para la elaboración de toda la discusión, se presentan algunas consideraciones iniciales sobre la importancia de la propuesta de investigación, referencias teóricas que podrán consubstanciar la investigación, una posibilidad de problema de investigación, demostraciones y procedimientos para la conducción de la investigación-acción, probable producto final y resultados esperados.
\end{abstract}

Palabras clave: Media Independiente, Referencial Didáctico, Enseñanza Media, Racismo Ambiental.

"Todo brasileiro, mesmo o alvo, de cabelo louro, traz na alma, quando não no corpo, a sombra, ou pelo menos a pinta, do indígena ou do negro..."

Gilberto Freyre (1992)

\section{INTROITO E JUSTIFICATIVA PARA A PROPOSTA DE PESQUISA}

As mídias independentes que estão fora da lógica empresarial, quando comprometidas socialmente e profissionalmente, divulgam as informações e notícias de forma ética, sustentável e responsável, com compromisso com os fatos que chegam às minorias negras, aos/às LGBTS, aos povos indígenas, às mulheres negras, outras categorias sociais historicamente oprimidas e à sociedade em geral.

Estes espaços midiáticos são profícuos para a produção de saberes dialógicos que possibilitam uma formação crítico-freiriana para a desconstrução de conceitos cristalizados fomentadores de estigmas que dão sustentação e naturalização a todas as nuances de injustiça e de racismo, dentre elas, as mais nefastas de todas, e quase nunca percebidas pelo tecido social - a Injustiça Ambiental e o Racismo Ambiental.

A sugestão em questão poderá ampliar o escopo do estado da arte e preencher lacunas 
em torno de discussões específicas no que concerne às potencialidades da mídia alternativa como referencial didático no Ensino Médio para uma formação crítica de combate às injustiças e ao Racismo Ambiental.

Como sugestão, o lócus objeto de estudo escolhido foi o CIEPS - Complexo Integrado de Educação de Porto Seguro e o nível básico de execução foi o Ensino Médio, mas esta opção é hipotética, dado que a pesquisa poderia ser executada em quaisquer espaços escolares, níveis, períodos e anos do Ensino fundamental e do Ensino Médio da Educação Básica Brasileira.

Para continuar a discussão, é oportuno destacar que a publicação de um trabalho de sugestão de pesquisa é deveras importante, pois contribui, de forma direta, para a alfabetização científica de graduandos e até de pós-graduandos que apresentam dificuldades no âmbito da elaboração de propostas de pesquisa para apresentação nas seleções de pósgraduação em todo o país. Muitos são reprovados logo na fase de projetos, por isto, este artigo desponta como oportunidade de reflexão em torno dos processos e dos caminhos de pesquisa para a elaboração de anteprojetos, projetos ou propostas de intervenção.

Ao considerar-se tal aspecto, pode-se mencionar que para o estudo em questão, é possível partir de um corpus midiático composto por três mídias independentes como Desacato, Alma Preta e ANF - Agência de notícias das favelas -, haja vista que estas mídias possuem uma vasta literatura jornalística que discute injustiça ambiental e racismo ambiental no Brasil e, por isso, despontam como fontes importantes de análise que servirão para a intervenção no Ensino Médio (doravante EM) no Complexo Integrado de Educação de Porto Seguro (ou em qualquer outro lócus que o futuro pesquisador escolha) em encontros com docentes da instituição para o debate em torno das potencialidades da mídia independente como referencial didático para uma formação crítica de combate à Injustiça Ambiental, ao Racismo Ambiental e a suas configurações na cidade, buscando compreender as noções e as percepções dos referidos professores acerca do fenômeno levantado, além de verificar como o tema é apresentado ao corpo discente pelos docentes participantes da pesquisa.

Com esta proposta, a partir dos resultados de pesquisa, mostrar-se-á que a mídia alternativa, como material de referência para os debates em sala de aula, possui potencialidades pedagógicas ainda pouco exploradas para uma formação crítico-freiriana, 
seja porque, muitas vezes, muitos docentes, inconscientemente, ainda estão presos à noção de que somente as mídias hegemônicas resultantes da colonialidade nos processos informacionais são os "melhores" espaços de informação ou porque muitos deles, de fato, desconhecem a abertura dialógica dos meios de comunicação não empresariais.

Com uma proposta nesta vertente será possível estudar as potencialidades da mídia independente como referencial didático para o EM no CIEPS com vistas a uma formação crítica em torno do combate à injustiça e ao Racismo Ambiental em Porto Seguro, ainda que a intersecção ensino nesse objeto triplo assuma papel importante, a grande questão da proposta será compreender os processos midiáticos como produtores de referencialidades didáticas nas fronteiras do saber formal e informal que imprimem sentidos às relações étnicoraciais, partindo do pressuposto de que Desacato, Alma Preta e ANF são espaços educativos não formais que, no cruzamento com um espaço formal de aprendizagem como o CIEPS pode se tornar fonte imprescindível para novas práxis docentes em torno da discussão da injustiça ambiental e do racismo ambiental, duas questões complementares pouco conhecidas ou, quando discutidas, sem a profundidade que elas exigem.

\section{REFERENCIAIS TEÓRICOS QUE PODERÃO CONSUBSTANCIAR A PROPOSTA DE PESQUISA}

O estudo das potencialidades da mídia independente como fonte ou referência didática nos debates nas práxis pedagógicas dos/as docentes do EM do CIEPS para o combate à injustiça e ao Racismo Ambiental comporta um marco teórico em torno de três campos do conhecimento - mídia, educação (a partir dos pressupostos freirianos de pedagogia para a autonomia e ruptura da educação bancária para a libertação) e injustiça-racismo ambiental, levando em conta que o objeto de estudo em baila é atravessado por esta tríade de questões.

Diante dessa fronteira tripla de estudos, para a análise do objeto proposto, faz-se imprescindível apresentar, de forma sintética, o estado da arte em torno desses três temas, pois, pela complexidade que abarca, seria quase impossível uma revisão bibliográfica completa.

Para fins de historicidade do surgimento e objetivos da mídia independente, também conhecida por cidadã ou alternativa, é interessante recorrer a Amorim et al (2012), quando se 
valem de Kucinski para afirmarem que, apesar da diversidade de propostas e tendências, alguns satíricos, outros políticos, feministas, ecológicos ou culturais, o que identificava o campo de atuação da imprensa alternativa era o combate "político-ideológico à ditadura, na tradição de lutas por mudanças estruturais" (KUCINSKI, 2001, p. 6), mas também criticavam severamente o capitalismo e o imperialismo.

Amorim et al (2012) também destacam que a partir da segunda metade da década de 1980 se observa que, na realidade, o que se chamou de fim ou de decadência da imprensa alternativa à época da ditadura militar, se constituiu na transformação dessa importante forma de comunicação. Não só ocorreu a mudança de temáticas, agora voltadas à cidadania, como também de formatos, principalmente com a rede mundial de computadores. Muitos alternativos de papel estão na internet ampliando o debate e o público. E o que era imprensa alternativa, passou agora a chamar-se de mídia alternativa, dada a possibilidade de abrigar as mais diversas formas de comunicação cidadã.

Feita esta historicidade, cabe apresentar o papel que exerce a mídia independente na conjuntura social-política brasileira e, para tanto, pode-se arvorar em Almeida e Evangelista (2013) quando afirmam que: "as mídias independentes se propõem a destacar enquadramentos diferenciados dos que estampam os grandes jornais ou são exibidos nos noticiários televisivos".

A escolha do objeto mídia independente, a partir de suas potencialidades como referência pedagógica, partiu de noções de mediação em Martín-Barbero (1997) de que a comunicação e os media são inerentes aos processos de produção de sentidos e de diferença cultural nas culturas contemporâneas e também da concepção de mídia para McLuhan (1972) compreendida como meio extensivo e não instrumental constituinte das ecologias cognitivas sociais.

Partindo-se do fato de que a mídia independente oferece a condição de, através da linguagem, acumular e transmitir experiência fora da lógica hegemônica, é oportuno fazer ponte com McLuhan (1972) a partir do homo faber, o homem criador de instrumentos - quer na fala, quer na escrita, quer no rádio, há muito se empenhando em atender um ou outro de seus órgãos dos sentidos a ponto de perturbar todos os seus outros sentidos e faculdades. (...) A busca irreprimível por um "encerramento", por uma "completação", ou por um novo equilíbrio, processa-se tanto pela supressão como pela extensão do próprio sentido ou função humana. 
Ao optar por mídias independentes como referenciais pedagógicos, pode-se partir do pensamento de Gindre (2004) de "mídia alternativa" como indicação àqueles que se colocam como uma opção ideológica ao mercado com projeto mais evidente de enfrentamento da chamada grande mídia.

Nesse bojo, também é importante recorrer à noção de comunicação midiatizada e mediadora das interações humanas em (MARTíN-BARBERO, 2006) como principal operador de sentidos sobre o que sabemos e entendemos do mundo ao nosso redor e como espaço público para a construção de visões de mundo que definem entendimentos e modos de ação sobre certa realidade e região.

Ainda no tocante à potencialidade da mídia alternativa como recurso didático para uso no EM no Complexo Integrado de Educação de Porto Seguro como arma discursiva para que os docentes construam saberes acerca do que são injustiça ambiental e racismo ambiental e como eles se configuram em Porto Seguro, é oportuno recorrer ao pensamento de Chomsky (2014) para compreender o papel que a mídia ocupa na política contemporânea, que somos obrigados a perguntar em que tipo de mundo e de sociedade deseja-se viver e, sobretudo, em que espécie de democracia se pensa quando se quer que essa sociedade seja democrática.

Ainda tecendo pontes entre o papel da mídia independente e as discussões sobre mídia em Martín-Barbero (2009 apud Barros in Mattos 2012) quando ele recoloca assim uma questão decisiva: a presença dos meios na vida social, não em termos puramente ideológicos, mas como uma capacidade de ver além dos costumes, ajudando o país a se movimentar. [...] invertendo um meu primeiro mapa e proponho as 'mediações comunicativas da cultura', que são: a 'tecnicidade'; a 'institucionalidade' crescente dos meios como instituições sociais e não apenas aparatos, instituições de peso econômico, político, cultural; a 'socialidade' [...] E, finalmente, as novas 'ritualidades' que acontecem em relação aos novos formatos industriais possibilitados pela tecnicidade. [...] Era preciso assumir não a prioridade dos meios, mas sim que 'o comunicativo está se transformando em protagonista de uma maneira muito mais forte'.

Após todas essas discussões sobre mídia e, mais especificamente, sobre as potencialidades da mídia independente, torna-se necessário elaborar uma discussão sobre racismo e injustiça ambiental e acerca destas expressões, para início de discussão, é interessante mencionar que são dois campos conceituais diferentes e complementares. 
Para traçar uma diferença conceitual entre as expressões é importante arvorar-se em Bullard (1990 apud HERCULANO (2006)) para entender Justiça Ambiental como “o conjunto de princípios que asseguram que nenhum grupo de pessoas, sejam grupos étnicos, raciais ou de classe, suporte uma parcela desproporcional das consequências ambientais negativas de operações econômicas, de políticas e programas federais, estaduais e locais, bem como resultantes da ausência ou omissão de tais políticas" É ainda "a busca do tratamento justo e do envolvimento significativo de todas as pessoas, independentemente de sua raça, cor, origem ou renda no que diz respeito à elaboração, desenvolvimento, implementação e reforço de políticas, leis e regulamentações ambientais" e mais uma vez em Herculano (2006) para perceber que o Racismo ambiental é o conjunto de ideias e práticas das sociedades e seus governos, que aceitam a degradação ambiental e humana, com a justificativa da busca do desenvolvimento e com a naturalização implícita da inferioridade de determinados segmentos da população afetados - negros, índios, migrantes, extrativistas, pescadores, trabalhadores pobres, que sofremos impactos negativos do crescimento econômico e a quem é imputado o sacrifício em prol de um benefício para os demais. O racismo ambiental seria, portanto, um objeto de estudo crítico da Ecologia Política (ramo das Ciências Sociais que examina os conflitos socioambientais a partir da perspectiva da desigualdade e na defesa das populações vulnerabilizadas). Ainda segundo Herculano (2006) para Bullard, o termo Justiça Ambiental acabou sendo mais funcional do que Racismo Ambiental, pois tem a ver com os pobres de todos os quadrantes e cores. A justiça ambiental é "um slogan maravilhoso", concorda Alier, ressaltando que, embora tenha tido inicialmente um sentido limitado, nos Estados Unidos, relativo à contaminação de minorias, é potencialmente amplo (Alier, 2004, p. 335).

Diante do fato de que as duas expressões ainda são conceitos em construção e que não existe unanimidade teórica acerca da questão, para a pesquisa proposta, estes dois termos serão compreendidos como diferentes e complementares.

Para compreender o que é o tal racismo ambiental pode-se recorrer a Santana, Câmara e Santos (2016) para a percepção de que para os homens negros e para as mulheres negras, as elites político-empresariais brancas sempre reservaram os rincões mais inóspitos do Brasil. 
Com base no conceito acima, tem-se, então, que ainda que o racismo ambiental seja uma discussão não muito difundida no Brasil, pelo menos, não entre todas as esferas da sociedade, ainda assim, ele existe como prática biopolítica há séculos e conforme o sociólogo Damatta (1986 apud Barros e Souza 2012), por todo transcorrer do século XX e ao início do século XXI observa-se uma República excludente, amparada em relações de poder autoritárias e clientelistas. As desigualdades existentes entre as camadas que compõem o povo brasileiro são percebidas tanto em uma leitura da realidade brasileira sob um enfoque institucionalista, que destaca os aspectos político-econômicos, bem como as mazelas sociais, como sob um enfoque culturalista, com ênfase ao elemento cotidiano dos usos e costumes, da nossa tradição patriarcal e alicerçada na família.

Como estudar injustiça e racismo ambiental exige conhecimento sobre racismo, de forma geral e, consequentemente, sobre a ultrapassada noção de raça, algumas reflexões em torno disso são necessárias para elucidar como os imaginários e preconceitos foram construídos a partir dos espaços históricos e sociais de fala e de práxis político-econômica acerca de uma suposta superioridade racial.

Na tese "Entre o "encardido", o "branco" e o "branquíssimo": raça, hierarquia e poder na construção da branquitude paulista", Schucman (2012), valendo-se de Munanga, apresenta-nos o seguinte: a ideia de raça e de racialização do mundo é, desde então, uma das explicações encontradas pela humanidade para classificar e hierarquizar os grupos humanos. No século XVIII, a cor da pele foi considerada um dos critérios dentro desse processo de classificação pela racialização e, dessa forma, a espécie humana ficou dividida em três raças, que permanecem até hoje no imaginário coletivo: branca, amarela e negra e que no século XIX acrescentaram ao critério de cor outros critérios morfológicos, como forma do nariz, lábios, queixos, ângulo facial etc.

Para Wedderburn (2007 apud Barros e Souza 2012), em sua obra "O racismo através da história: da antiguidade à modernidade", contribui, de modo substancial, para a compreensão da gênese do racismo ao abordar que um dos maiores problemas que desafia as disciplinas humanas é o do posicionamento da origem e do desenvolvimento do racismo na história. Tratar deste tema implica, também, elucidar outro problema não menos contencioso, a questão de raça. 
Moutinho-da-Costa (2011) afirma que raça é uma categoria mental da modernidade e cita Quijano $(1992,2005)$ que ela não tem história conhecida antes da América, tendo sido aplicada inicialmente aos índios e não aos negros, identidades sociais que ainda estavam sendo formadas. Ainda em relação ao conceito de raça, é importante conhecer sua construção histórica, pois ainda que ele tenha sido desconstruído pela ciência contemporânea, o racismo existe há séculos e, para elucidar esta questão, é importante entender que a classificação da humanidade em raças hierarquizadas desembocou em uma teoria pseudocientífica, a raciologia, que ganhou muito espaço no início do século XX. Na realidade, apesar da máscara científica, a raciologia tinha um conteúdo mais doutrinário do que científico a partir de Munanga (2003).

É oportuno destacar que estes preconceitos racistas que fomentaram a Primeira e Segunda Guerra Mundial teimam em existir no Brasil, em outras partes do Planeta e neles estão embriões importantes para entender o racismo em geral, as injustiças ambientais e o racismo ambiental. A ideia de supremacia de uma nação sobre a outra é, por exemplo, uma construção de racismo ambiental externo. No caso do Brasil, por conta das construções coloniais que teimam em perdurar na pós-modernidade, o racismo ambiental também se constrói no plano interno, a partir de conceitos obsoletos de superioridades de raças. A elite branca de capitalismo dependente, detentora do capital e dos meios hegemônicos de comunicação do país, continua operando discursivamente sob a ótica da colonialidade, por isso, é preciso descontruir toda a parafernália construída por essas aparelhagens ideológicas a serviço do Estado-Branco-Macho-Hétero-Racista-Burocrático-Opressor.

Com a Globalização, alguns processos que estavam isolados em relação a racismo vieram à tona em várias partes do Planeta e, no Brasil, para entender como o racismo ambiental se constrói, pode-se recorrer às noções apresentadas por Leff (2006) quando ele coloca que em face do processo de globalização regido pela racionalidade econômica e as leis do mercado está emergindo uma política do lugar, do espaço e do tempo mobilizada por novos direitos culturais dos povos. Nesse sentido, é oportuno ancorar-se em Moutinho-da-Costa quando esta se vale de Aníbal Quijano para dizer que a classificação social da população mundial de acordo com a ideia de raça foi, e ainda é, um dos eixos fundamentais do capitalismo, ou melhor, de um padrão de poder mundial que nasceu com a constituição da América e do que esse autor chama de capitalismo colonial/moderno e eurocentrado, a ponta 
de um sistema de poder Sistema-Mundo, na perspectiva de Immanuel Wallerstein (QUIJANO, 2005, pp. 227-229 apud Moutinho-da-Costa, 2011).

Fazendo a ponte com o que se afirma acima e o racismo ambiental, é oportuno mencionar que, na atualidade, os atores sociais que ocupam os espaços de degradação ambiental são as populações negras e os pobres de forma geral. Nesse sentido, é interessante fazer intersecção entre o que se afirmou e o que discorre Pacheco (2008) para entender que o racismo ambiental se refere às injustiças sociais e ambientais que recaem de forma implacável sobre etnias e populações mais vulneráveis, que ele não se configura apenas através de ações que tenham uma intenção racista, mas, igualmente, através de ações que tenham impacto "racial".

Cônscios de todos esses conceitos acerca de injustiça ambiental e racismo ambiental, os professores do CIEPS (ou de qualquer outro lócus de pesquisa em qualquer parte do Brasil) propiciarão aos seus discentes a capacidade de reflexão em torno do combate a todas essas formas históricas biopolíticas de opressão para outro mundo possível através do que Leff (2006) traz: que "o território éo lócus dos desejos, demandas e reclamos da população para reconstruir seus mundos de vida e reconfigurar suas identidades através de suas formas culturais de valorização dos recursos ambientais de novas estratégias de reapropriação da natureza".

Por fim, com relação ao marco teórico da educação, já que a proposta de pesquisa propõe-se a discutir não somente o potencial da mídia independente como referencial para o reconhecimento e combate às formas de injustiça e de racismo ambiental em Porto Seguro, mas de que forma isso ocorre no contexto da sala de aula, será apresentado ao corpo docente do CIEPS que é possível trabalhar todas estas questões a partir do aporte de Freire de que "O que caracteriza a comunicação enquanto este comunicar comunicando-se, é que ela é diálogo, assim como o diálogo é comunicativo." (1983, p. 67) - quanto na educação - "A educação é comunicação, é diálogo, na medida em que não é transferência de saber, mas um encontro de sujeitos interlocutores, que buscam a significação dos significados." (1983, p. 69). Ademais, cabe destacar que no que tange ao campo teórico da educação, para fins de justificativa, é interessante mencionar que ele não aparece aqui de forma ampla, pois, como salientado logo no início da proposta de pesquisa, toda a discussão em torno das potencialidades da mídia independente como referencial para novas práxis pedagógicas no EM no CIEPS se arvorará nas ideias e pressupostos teóricos de Freire (2000) de que "Ensinar exige reflexão crítica sobre a prática". 


\section{DEFINIÇÃO DE UM SUPOSTO PROBLEMA DE INVESTIGAÇÃO-AÇÃO PARA A CONSECUÇÃO DA PESQUISA}

O EM do Complexo Integrado de Educação de Porto Seguro é um lócus profícuo para a discussão da problemática do racismo ambiental e de suas configurações na cidade, no entanto, por este ser um tema ainda pouco difundido, a escola não o discute ou quando o faz é de forma não embasada ou fundamentada, dado que o livro didático apresenta lacunas nesse âmbito e as discussões existentes sobre o tema são mais recorrentes na universidade, espaço distante da realidade discursiva da Educação Básica. Diante da ausência de materiais que se interseccionem com as dialogicidades do público-alvo do CIEPS, é preciso apresentar aos docentes da instituição as potencialidades das mídias alternativas como Desacato, Alma Preta e ANF - Agência de notícias das favelas - como esferas públicas contemporâneas de referencialidades e caminhos para um ensino e aprendizagem libertário a partir do marco freiriano de debates para a construção de novos sentidos e percepções sobre as relações étnico-raciais no combate a todas as formas de racismo e, em especial, ao racismo ambiental.

\section{PROVÁVEIS PROCEDIMENTOS PARA A PESQUISA-INTERVENÇÃO}

No geral, esta pesquisa se enquadra em um gênero de caráter prático, com objetivo exploratório e explicativo por meio de uma abordagem qualitativa e natureza aplicada. Pelo contorno de intervenção que esta proposta de pesquisa assume e diante do fenômeno de pesquisa "Mídia independente como referencial didático no EM do CIEPS para uma formação crítica de combate à injustiça-racismo ambiental em Porto Seguro" o método de investigação utilizado será a pesquisa-ação partindo-se da noção de Thiollent (1997) de que a pesquisa-ação consiste essencialmente em acoplar pesquisa e ação em um único processo, no qual os atores implicados participam, junto com os pesquisadores, para chegarem interativamente a elucidar a realidade em que estão inseridos, identificando problemas coletivos, buscando e experimentando soluções em situação real. Simultaneamente, há produção e uso de conhecimento.

Ao optar por um gênero de pesquisa de caráter prático, levou-se em conta o fato de que o fenômeno de pesquisa em baila se configura como pesquisa ligada à prática de 
conhecimento científico para fins explícitos de intervenção na realidade, já em relação ao objetivo duplo, exploratório e explicativo, isso se deveu à ideia aceita de que o objetivo exploratório proporciona maior familiaridade com o problema, com vistas a torná-lo mais explícito ou construir hipóteses e o explicativo preocupa-se em identificar os fatores que determinam ou contribuem para a ocorrência de fatos e/ou fenômenos em determinada realidade, fatores presentes nesta pesquisa. Diante desse objetivo duplo, como pesquisador, haverá uma familiaridade com o fenômeno de pesquisa para, em seguida, a partir de encontros com os docentes do CIEPS, aplicar questionários semiestruturados, analisar o que se entende por injustiça e racismo ambiental, como se configuram em Porto Seguro e como é possível trabalhá-los em sala de aula na ausência de referenciais ou de fontes nos livros didáticos de forma crítica.

Como o planejamento de uma pesquisa-ação é muito flexível, a partir dos encontros com os docentes do CIEPS para a investigação do fenômeno de pesquisa deste trabalho, serão organizados seminários para a discussão das potencialidades da mídia alternativa como fontes de ensino e pesquisa para o combate à injustiça e ao racismo ambiental, a técnica principal para a condução da pesquisa será a de seminários com vistas a examinar o que os docentes do CIEPS compreendem acerca do tema e de que forma o apresentam em sala de aula, discutir e tomar decisões acerca do processo de investigação. Diante dessa flexibilidade, na primeira etapa da pesquisa serão feitas leituras bibliográficas, fichamentos e levantamento de textos que foram publicados nas três mídias independentes sobre o tema de pesquisa; na segunda etapa: haverá encontros com os professores a partir de seminários, aplicação de questionários semiestruturados para a análise do que eles entendem por racismo ambiental, suas configurações em Porto Seguro e como isso é trabalhado nas aulas em seus respectivos componentes curriculares no EM; na terceira etapa: terá início a análise de dados a partir do discurso dos docentes captados a partir dos encontros, seminários e das respostas para os questionários aplicados. Independente dos resultados, novos seminários e círculos horizontais de debate serão propostos acerca das potencialidades das mídias independentes como referenciais didáticos e fontes de pesquisa, de informação e de ensino para se discutir o que é injustiça ambiental, racismo ambiental, como se materializaram historicamente em Porto Seguro e como é possível combatê-los; na quarta etapa: terá início a organização de coletânea didática em formato apostila com textos que discutam injustiça e racismo ambiental e suas configurações em Porto Seguro a partir das três mídias independentes Desacato, Alma Preta e ANF bem como a construção de mapa pedagógico da cidade 
identificando os bairros com mais problemas ambientais e descaso do poder público local, para cotejar estas informações com dados de censos com caracterizações étnico-raciais das populações por bairro na cidade através da biblioteca do IBGE e do Atlas racial Brasileiro; já na quinta e última etapa: haverá a elaboração do trabalho final de pesquisa seguido de defesa no próprio CIEPS para, desta forma, os docentes que participaram da pesquisa, tenham acesso a todo o resultado da investigação científica. Após a defesa da dissertação ou trabalho final de curso, será apresentado um esboço de livro com reflexões sobre injustiças ambientais e racismo ambiental com base na coletânea pedagógica e no mapa pedagógico da cidade com exemplos de atividades que poderão ser utilizadas no EM para o desenvolvimento de novas consciências e percepções docentes acerca das relações étnico-raciais que possibilitem práxis pedagógicas combativo-libertárias.

\section{UM PROVÁVEL PRODUTO FINAL A SER PRODUZIDO A PARTIR DA PESQUISA}

Coletânea pedagógica com textos que discutam injustiça ambiental, racismo ambiental e suas configurações em Porto Seguro a partir das mídias independentes Desacato, Alma Preta e ANF. Construção de mapa pedagógico identificando os bairros com mais problemas socioambientais e descaso do poder público local a partir da biopolítica do abandono, para cotejar estas informações com censos com caracterizações étnico-raciais das populações por bairro na cidade a partir de dados do IBGE, do Atlas Racial Brasileiro e materiais em âmbito local. Ao final, publicar um livro com reflexões sobre injustiça e racismo ambiental a partir da coletânea elaborada e do mapa pedagógico seguido de atividades que poderão ser utilizadas no Ensino Médio para o desenvolvimento de novas consciências e percepções docentes e discentes acerca das relações étnico-raciais que possibilitem o combate às injustiças e ao racismo ambiental em Porto Seguro. 


\section{POSSIBILIDADES NO QUE CONCERNE A RESULTADOS ESPERADOS}

Espera-se com esta pesquisa, além do produto final que será gerado, abrir dialogicidades contínuas com o grupo investigado, no caso, os docentes do Complexo Integrado de Educação de Porto Seguro, para que, desta forma, sejam possíveis reflexões docentes coletivas que deem sustentação a autorreflexões pedagógicas.

A partir dessas intersecções dialógicas, pesquisador e sujeitos de pesquisa perceberão que a construção cognitiva e empírica através de reflexões críticas coletivas propiciará a emancipação e a libertação das condições da opressão. Tudo isso levando em consideração as vozes dos sujeitos da pesquisa, partindo da ideia de Franco (2005) de que a condição para ser pesquisa-ação crítica é o mergulho na práxis do grupo social em estudo, do qual se extraem as perspectivas latentes, o oculto, o não familiar que sustentam as práticas, sendo as mudanças negociadas e geridas no coletivo.

Diante das dialogicidades, na fronteira entre saberes do pesquisador e vozes dos sujeitos de pesquisa, todos os atores sociais envolvidos na pesquisa, inclusive o pesquisador, a partir de uma concepção sociológico-político-pedagógica crítica poderão reconhecer na mídia alternativa, independente ou cidadã, um corpus de referência de ensino e de informação exterior ao livro didático em torno de um tema tão importante como injustiça e racismo ambiental em Porto Seguro para novas percepções nas relações étnico-raciais e combate discursivo a todas as formas de racismo e injustiça, dentre eles, o ambiental, mal que assola o Brasil há séculos.

A partir desta pesquisa serão produzidas informações e construídos conhecimentos de uso pedagógico mais efetivo que promovam outras dialéticas acerca das injustiças e do racismo ambiental, problemática que interfere, diretamente, na vida de todos/as os/as atores/atrizes sociais de aprendizagem dentro e fora da escola, partindo-se do pressuposto de que esta é um microcosmo de tessituras macroscópicas sociais da cidade. 


\section{REFERÊNCIAS}

ALIER, Joan Martinez. El Ecologismo de los pobres. Barcelona: Içaria, 2004. In: HERCULANO, Selene. Lá como cá: conflito, injustiça e racismo ambiental. Texto apresentado no I Seminário Cearense contra o Racismo Ambiental. Fortaleza, 20 a 22 de novembro de 2006.

ALMEIDA, Thiago D’Angelo Ribeiro. EVANGELISTA, Amanda Falcão. Tecnologias móveis, mídias independentes e coberturas de mobilizações sociais urbanas: as influências do "midialivrismo" na sociedade midiatizada. Centro Internacional de Semiótica e Comunicação - CISECO II COLÓQUIO SEMIÓTICA DAS MÍDIAS• ISSN 2317-9147. Praia Hotel Albacora• Japaratinga - Alagoas. 25 de setembro de 2013.

AMORIM, Célia Regina Trindade Chagas; CASTRO, Mariana Costa; MACHADO, Roberta Aragão; OLIVEIRA, Ana Cruz de. $O$ contexto da Imprensa Alternativa na Amazônia no período da ditadura militar (1964-1985). Intercom - Sociedade Brasileira de Estudos Interdisciplinares da Comunicação. XI Congresso de Ciências da Comunicação na Região Norte - Palmas - TO - 17 a 19/05/2012.

BULLARD, Robert D. Dumping in Dixie: race, class and environmental quality. Boulder, Westview Press, 1990. In: HERCULANO, Selene. Lá como cá: conflito, injustiça e racismo ambiental. Texto apresentado no I Seminário Cearense contra o Racismo Ambiental. Fortaleza, 20 a 22 de novembro de 2006.

CHOMSKY, Noam. Mídia: propaganda política e manipulação. São Paulo: Martins Fontes, 2014.

DAMATTA, Roberto. Explorações: ensaios de sociologia interpretativa. Rio de Janeiro: Rocco, 1986. In: BARROS, Judson e SOUZA, Carmo Antonio de. Aspectos históricos e socioculturais justificadores da imprescritibilidade do crime de racismo. Planeta Amazônia: Revista Internacional de Direito Ambiental e Políticas Públicas. Macapá, n. 4, p. 23-36, 2012.

FRANCO, Maria Amélia Santoro. Pedagogia da Pesquisa-ação. Revista Educação e Pesquisa, São Paulo, v. 31, n. 3, p. 483-502, set/dez, 2005.

FREIRE, Paulo. Extensão ou Comunicação? Tradução de Rosisca Darcy de Oliveira. 7. ed. Rio de Janeiro: Paz e Terra, 1983.

Terra, 2000.

. Pedagogia da autonomia: saberes necessários à prática educativa. 15ª ed. São Paulo: Paz e

FREYRE, Gilberto. Casa-Grande e senzala. Rio de Janeiro: Record, 1992, p. 307.

GINDRE, Gustavo. A sociedade civil brasileira e a luta pela democratização das comunicações. Fundação Ford, $2004 . \quad$ Disponível em: http://www.direitoacomunicacao.org.br/novo/content.php?option=com_docman\&task=search_result. Acesso em 12 de março de 2018.

HERCULANO, Selene. Lá como cá: conflito, injustiça e racismo ambiental. Texto apresentado no I Seminário Cearense contra o Racismo Ambiental. Fortaleza, 20 a 22 de novembro de 2006.

KUCINSKI, Bernardo. Jornalistas e Revolucionários: Nos tempos da imprensa alternativa. São Paulo: Eccentric Duo, 2001. In: AMORIM, Célia Regina Trindade Chagas; CASTRO, Mariana Costa; MACHADO, Roberta Aragão; OLIVEIRA, Ana Cruz de. O contexto da Imprensa Alternativa na Amazônia no período da ditadura militar (1964-1985). Intercom - Sociedade Brasileira de Estudos Interdisciplinares da Comunicação. XI Congresso de Ciências da Comunicação na Região Norte - Palmas - TO - 17 a 19/05/2012.

LEFF, Enrique. Racionalidade ambiental: a reapropriação social da natureza. Rio de Janeiro: Civilização brasileira, 2006.

MARTÍN-BARBERO, Jesús. Dos meios às mediações: comunicação, cultura e hegemonia. Rio de Janeiro: Editora UFRJ, 1997. 
. Dos meios às mediações: comunicação, cultura e hegemonia. Prefácio: Néstor García Canclini. 4. ed. Rio de Janeiro: UFRJ, 2006.

. Uma aventura epistemológica. Entrevistador: Maria Immacolata Vassalo de Lopes. Matrizes, São Paulo, v. 2, n. 2, p. 143-162, 2009. In: BARROS, L. M. Recepção, mediação e midiatização: conexões entre teorias europeias e latino-americanas. In: MATTOS, M. A., JANOTTI JUNIOR, J., and JACKS, N., orgs. Mediação \& midiatização [online]. Salvador: EDUFBA, 2012, pp. 79-105. ISBN 978-85-232-1205-6. Available from SciELO Books http://books.scielo.org. Acesso em 12 de janeiro de 2018.

MCLUHAN, Marshall. A Galáxia de Gutemberg: a formação do homem tipográfico. São Paulo: Editora Nacional. Editora da USP, 1972.

MOUTINHO-DA-COSTA, Lara. Territorialidade e racismo ambiental: elementos para se pensar a educação ambiental crítica em unidades de conservação. Pesquisa em Educação Ambiental, vol. 6, n. pp. 101-122, 2011.

MUNANGA, Kabengele. Uma abordagem conceitual das noções de raça, racismo, identidade e etnia. Palestra proferida no 3o Seminário Nacional Relações Raciais e Educação-PENESB-RJ, 2003.

PACHECO, Tânia. Racismo ambiental: expropriação do território e negação da cidadania. In: Secretário de Meio Ambiente e Recursos Hídricos. Superintendência de Recursos Hídricos (Bahia). Justiça pelas águas: enfrentamento ao racismo ambiental. Salvador: Superintendência de Recursos Hídricos, 2008.

QUIJANO, A. Raza, etnia, nación en Mariátegui: cuestiones abiertas. In: FORGUES, R. (Org.). José Carlos Mariátegui y Europa. La otra cara del descubrimiento. Lima: Amauta, 1992. In: MOUTINHO-DA-COSTA, Lara. Territorialidade e racismo ambiental: elementos para se pensar a educação ambiental crítica em unidades de conservação. Pesquisa em Educação Ambiental, vol. 6, n. 1 pp. 101-122, 2011.

Colonialidade do poder, eurocentrismo e América Latina. In: LANDER, E. (Org.). A Colonialidade do Saber, Eurocentrismo e Ciências Sociais. Buenos Aires: CLACSO, 2005. In: MOUTINHO-DA-COSTA, Lara. Territorialidade e racismo ambiental: elementos para se pensar a educação ambiental crítica em unidades de conservação. Pesquisa em Educação Ambiental, vol. 6, n. 1 pp. 101-122, 2011.

SANTANA, Elissandro dos Santos. CÂMARA, Denys Henrique Rodrigues e SANTOS, Joceneide Cunha dos. Racismo ambiental no Brasil. Rio de Janeiro: Revista Ecodebate, 2016.

SCHUCMAN, Lia Vainer. Entre o "encardido", o "branco" e o "branquíssimo": Raça, hierarquia e poder na construção da branquitude paulistana. Tese de Doutorado, Instituto de Psicologia, Universidade de São Paulo, São Paulo, 2012.

THIOLLENT, M. Pesquisa-Ação nas Organizações. São Paulo: Atlas, 1997.

WEDDERBURN, Carlos Moore. 0 racismo através da história: da Antiguidade à Modernidade. Disponível em: http://www.abruc.org.br/sites/500/516/00000672.pdf. Acesso em 20 de março de 2018.

$O$ racismo através da história: da antiguidade à modernidade. Belo Horizonte: Ed. Mazza, 2007. In: BARROS, Judson e SOUZA, Carmo Antonio de. Aspectos históricos e socioculturais justificadores da imprescritibilidade do crime de racismo. Planeta Amazônia: Revista Internacional de Direito Ambiental e Políticas Públicas. Macapá, n. 4, p. 23-36, 2012. 